\title{
LEVANTAMENTO FAUNÍSTICO DOS CRUSTÁCEOS DECÁPODES (ANOMURA, BRACHYURA) NO LITORAL CAPIXABA
}

\author{
Crislene Cristo Ribeiro' \\ Larissa Bettcher Brito ${ }^{2}$ \\ Erika Takagi Nunes ${ }^{3}$ \\ Adriane Araújo Braga ${ }^{4}$
}

Resumo: Levantamento faunístico dos crustáceos decápodes é de fundamental importância para o conhecimento das comunidades, servindo de base para a conservação da biodiversidade. O objetivo deste estudo foi analisar a fauna dos Anomura e Brachyura em dois costões rochosos, localizados em Anchieta e Guarapari, litoral do Espírito Santo, com ênfase na análise dos índices de diversidade e similaridade entre as espécies. Em cada região, foram amostrados quatro pontos ( $P 1, P 2, P 3$ e P4), durante o período de outubro/2014 a setembro/2015. A diversidade de Shannon Wiener e equitabilidade foram calculados, bem como, o grau de semelhança entre as espécies. Foram coletados 3.156 indivíduos (1.022 em Anchieta e 2.134 em Guarapari), sendo representados por oito famílias e 14 espécies. O maior valor de diversidade foi encontrado no P1 e P2 em Anchieta, além do P1 ter apresentado o maior valor de equitabilidade. As espécies com abundância e ocorrência semelhantes foram agrupadas com maior similaridade. Os locais estudados apresentam condições favoráveis para o desenvolvimento e estabelecimento desses crustáceos anumuros e braquiúros.

Palavras-chave: Diversidade; Equitabilidade; Similaridade; Abundância; Riqueza.

\footnotetext{
${ }^{1}$ Programa de Pós Graduação em Ciências Biológicas (Zoologia)/Universidade Estadual Paulista, Brasil. E-mail: crislenebio@yahoo.com.br.

2 Ciências Biológicas Licenciatura/Universidade Federal do Espírito Santo, Brasil. E-mail: larissa_bettcher@hotmail.com.

${ }^{3}$ Departamento de Biologia/Universidade Federal do Espírito Santo, Brasil. E-mail: erikatnunes@yahoo.com.br

4 Departamento de Biologia/Universidade Federal do Espírito Santo, Brasil. E-mail: dricrab@yahoo.com.br
} 